\title{
Women's Performance of Breast Cancer Screening (Breast Self-Examination, Clinical Breast Exam and Mammography)
}

\author{
Somaya Aljohani*, Israa Saib, Muatasim Noorelahi \\ Intern, College of Medicine, Taibah University, Medina, KSA \\ Email: *somaya.aljohani@gmail.com
}

How to cite this paper: Aljohani, S., Saib, I. and Noorelahi, M. (2017) Women's Performance of Breast Cancer Screening (Breast Self-Examination, Clinical Breast Exam and Mammography). Advances in Breast Cancer Research, 6, 16-27. http://dx.doi.org/10.4236/abcr.2017.61002

Received: December 5, 2016

Accepted: December 25, 2016

Published: December 28, 2016

Copyright (@) 2017 by authors and Scientific Research Publishing Inc. This work is licensed under the Creative Commons Attribution International License (CC BY 4.0).

http://creativecommons.org/licenses/by/4.0/

\section{(c) (i) Open Access}

\begin{abstract}
Background: Breast cancer is the most common malignancy among women in Saudi Arabia. Despite the availability of early detection methods to diagnose breast cancer, a huge number of women are still unaware about these methods. This study was conducted to identify the attitude of women in Medina toward breast cancer screening methods, including breast self-examination (BSE), clinical breast examination (CBE) and mammography. Methods and Materials: A cross-sectional survey has been conducted on 124 women aged from 39 and older, who attended Taibah Medical Center for cancer screening either by doctor's recommendation, family or friends advice, or by herself. Face to face questionnaire was used to collect data. All data were analyzed by statistical analysis system software. Results: The results showed only $35.5 \%, 27.4 \%$ and $37.8 \%$ of participants reported that they practiced BSE, CBE and annual mammography, respectively. Only $27.3 \%$ of women practiced BSE once per month, and $8.8 \%$ visited doctor annually for CBE. Both educational level $(p=0.004)$ and family history $(\mathrm{p}=0.01)$ were significantly related to BSE. $57.7 \%$ of the participants who had positive family history practiced BSE, and $56.0 \%$ of the participants who practiced BSE were highly educated. Lacking awareness about BSE is the most important barrier in not practicing BSE, while not having a breast lump was the reason for not undergoing either clinical breast examination (38.7\%) or periodic mammography (54.9\%). Conclusion: This study emphasized the need for massive health education program to increase awareness, and improve the attitude of women toward breast cancer screening methods.
\end{abstract}

\section{Keywords}

Breast Cancer, Screening, Self-Examination, Mammography

\section{Introduction}

Breast cancer is the most frequent malignancy among Saudi women and the 
ninth leading cause of death in Saudi Arabia in 2010 [1] [2]. Breast cancer incidents have been escalating faster in the Kingdom and breast cancer is currently ranked number one among cancerous diseases in women in the country of Saudi Arabia [3] [4]. Breast cancer is the second leading cause of mortality and morbidity in women of western countries [5].

Breast cancer is preventable through early detection and healthy lifestyles that improve women's health and decrease the costs relating to cancer death [6]. Therefore, effective screening programs are the best way to detect cancer before experiencing any symptoms [7]. Breast cancer screening methods include breast self-examination (BSE), clinical breast examination (CBE) and mammograms [8]. These effective ways of screening are consistent with and show that there is relatively little current emphasizing on the first published results of the New York randomized control trial in 1997 [9].

Ravichandran et al., conducted a study in the Riyadh region that revealed only $23.1 \%$ of studied subjects practiced BSE [10]. Hussein et al. carried out a study on 1000 participants in Hail city and its rural neighborhoods, and found that $50 \%$ of all female participants $>16$ years old did not practice BSE [11]. Some studies were based on selected groups, like students, and findings revealed an imbalance between the knowledge and practice of BSE, CBE and mammogram [12].

However, in the Gulf region, specifically in Saudi Arabia several previous studies conducted in different regions that assessed the awareness, knowledge, and attitude towards breast cancer among female Saudi teachers, female university students, and women respectively, indicated that many women are still lacking information about breast cancer screening [13] [14].

Despite the spread of breast cancer screening centers in Saudi Arabia that offer free screening service, many women have no access to the screening program due to several factors like culture, environment, lack of education and awareness among females; and most importantly, lack of social support that incorporates lack of encouragement by a physician [15].

Health care should keep in mind that social support within hospitals and clinics is an essential component of a clinical encounter [16]. A study by Jensen et al. indicated that a low level of social support was strongly associated with nonparticipation in and non-adherence to breast cancer screening [17], thus posing a major public health concern. The review of literature revealed that there are no published studies about this community issue in Medina, Saudi Arabia. We aimed to further evaluate such conditions for these women in this city and help them become more pragmatic in their own life.

\section{Objective}

To identify the prevalence and effectiveness in breast cancer screening methods among women.

\section{Subjects and Methods}

This study was carried out to investigate the attitude of women about breast 
cancer screening by using a cross-sectional survey of women aged from 39 years and older who were attending Taibah Medical Center for breast cancer screening for a period of four months (2015-2016). The sample comprised 124 Saudi and non-Saudi females who visited the center for a mammogram. A face-to-face survey (10 minutes per each subject) was used to collect the data after obtaining written consent from each participant.

The study employed a predesigned structured, reliable and validated questionnaire to collect the data. Those who refused to participate or gave incomplete information were excluded from the study. Study approval was obtained from the Ethics Committee of Taibah College of Medicine, Medina, Saudi Arabia (TUCD-REC). A consent form was given at the beginning of the questionnaire explaining the purpose of the study, and requested their voluntary participation. The women's privacy and confidentiality were assured.

The questionnaire was constructed based on the objective of the study, including questions on socio-demographic data (such as: age, marital status, nationality, education level, work status and income), a commitment to do a breast checkup including breast self-examination, breast clinical examination and mammogram as well as their reasons for not doing them.

All data was analyzed using the statistical analysis system (SAS) software package [18]. Data was presented using frequencies. The women's practice of breast cancer screening (breast self-examination, clinical breast examination and mammography) was assessed and compared by women's characteristics using appropriate statistical tests (Chi square and Fischer exact test). The criteria of significance were considered at a $\mathrm{P}$-value of $\leq 0.05$. Furthermore, the barrier items preventing women from the practice of the studied breast cancer screening methods were assessed by the frequency number and percent of each studied barrier item for each studied breast cancer screening.

\section{Results}

During the study period, 124 women were interviewed at Medina cancer screening center at Medina city, Saudi Arabia. Fifty women (40.3\%) visited the center according to doctors' recommendation, 27 women according to their family and friends talks and 47 (38\%) by women herself.

Of the studied 124 women, there were 71 women (57.3\%) reported that they practiced mammography for the first time during their life and the remaining 53 (42.7\%) women had reported to practice mammography regularly. Of those 53 women, $20(37.8 \%)$ had practiced mammography once every year, 7 (13.2\%) every two years, 26 (49\%) every three years. Of all the women studied, 63 women reported that they have been referred by doctors to do the mammography.

Of the studied 124 women, there were $44(35.5 \%)$ reported that they practice BSE and 34 (27.4\%) reported that they practice clinical examination.

Among the studied women reporting breast self-examination (44 out of 124), there have been 13 women (27.3\%) practicing BSE once monthly, only 5 women (11.3\%) do it 2 - 3 days after their period ends, 26 women (59\%) examine the 
breast while lying down, 34 (77.3\%) raise their arms up and look for changes, 23 (52.3\%) examine and press their nipples for any type of discharge, and 32 (73\%) examine lymph nodes in their armpit.

Of the studied women practicing clinical breast examination (34 out of 124), 3 women $(8.8 \%)$ reported that they visited a doctor to examine their breasts every 2 months, 13 (38.3\%) every 6 months, 3 (8.8\%) every year and 15 (44.1\%) every three years.

Table 1 presented the characteristics of the studied 124 women. Half of the studied women were aged $\geq 50$ years, and $76.6 \%$ of the studied women were Saudis. About three-fourth of the studied women were married (72.6\%), and didn't work (house wife) $(76.6 \%)$, and less than university educated $(79.8 \%)$. The majority of the studied women (96.8\%) reported less than 20,000 SR as family's monthly income. The studied women reported that they have had a positive family history regarding breast cancer and having breast problems were $21.0 \%$ and $34.7 \%$, respectively. The contraceptive pill use was $2.4 \%$ among all studied women while the ex-users were $56.7 \%$.

Table 1. Characteristics of the studied women.

\begin{tabular}{|c|c|}
\hline Characteristics $^{*}$ & $\mathrm{~N}=124$ \\
\hline \multicolumn{2}{|l|}{ Age in years } \\
\hline$<40$ & $3(2.4)$ \\
\hline $40 \leq 50$ & $59(47.6)$ \\
\hline$\geq 50$ & $62(50.0)$ \\
\hline \multicolumn{2}{|l|}{ Nationality } \\
\hline Saudi & $95(76.6)$ \\
\hline Non Saudi & $29(23.4)$ \\
\hline \multicolumn{2}{|l|}{ Marital status } \\
\hline Single & $1(0.8)$ \\
\hline Married & $90(72.6)$ \\
\hline Widow and divorced & $33(26.6)$ \\
\hline \multicolumn{2}{|l|}{ Occupation } \\
\hline House wife & $95(76.6)$ \\
\hline Employed & $22(17.7)$ \\
\hline Retired & $7(5.7)$ \\
\hline \multicolumn{2}{|l|}{ Educational level } \\
\hline Illiterate & $25(20.2)$ \\
\hline Basic & $74(59.6)$ \\
\hline University and higher & $25(20.2)$ \\
\hline \multicolumn{2}{|c|}{ Family monthly income in SR } \\
\hline$<5000$ & $50(40.3)$ \\
\hline $5000-20,000$ & $70(56.5)$ \\
\hline$>20,000$ & $4(3.2)$ \\
\hline \multicolumn{2}{|c|}{ Family history of breast cancer } \\
\hline Yes & $26(21.0)$ \\
\hline No & $98(79.0)$ \\
\hline \multicolumn{2}{|l|}{ Having breast problem } \\
\hline Yes & $43(34.7)$ \\
\hline No & $81(65.3)$ \\
\hline
\end{tabular}

${ }^{*}$ Data are presented by $\mathrm{n}(\%) .{ }^{*}$ Breast self-examination. 
Table 2 showed the distribution of breast self-examination among the studied women by their characteristics. The higher significant proportion of women who practice breast self-examination are young women less than 40 years (100\%) and those from 40 to less than 50 years (38.9\%), highly educated women (56\%), high monthly income women (75\%) and those reported positive family history for breast cancer (57.7\%). Although not significant, the proportion of breast selfexamination was higher among non-Saudis, married and divorced, employed and retired, women having breast problems, and contraceptive pill users and ex-users.

Table 3 presented practice of clinical breast examination among the studied women by their characteristics. Significant high proportions of women were found to do clinical breast examination among employed (41.1\%), retired women

Table 2. Breast self-examination among the studied women by their characteristics.

\begin{tabular}{|c|c|c|c|}
\hline \multirow{2}{*}{ Socio-demographic characteristics } & \multicolumn{2}{|c|}{ Breast self-examination } & \multirow{2}{*}{$P$ value } \\
\hline & Yes $(n=44)$ & No $(n=80)$ & \\
\hline \multicolumn{4}{|l|}{ Age in years } \\
\hline$<40$ & $3(100.0)$ & $0(0.0)$ & \\
\hline $40 \leq 50$ & $23(38.9)$ & $36(61.1)$ & \\
\hline$\geq 50$ & $18(29.3)$ & $44(70.7)$ & $0.03^{*}$ \\
\hline \multicolumn{4}{|l|}{ Nationality } \\
\hline Saudi & $31(32.6)$ & $64(67.4)$ & \\
\hline Non Saudi & $13(44.8)$ & $16(55.2)$ & 0.23 \\
\hline \multicolumn{4}{|l|}{ Marital status } \\
\hline Single & $0(0.0)$ & $1(100.0)$ & \\
\hline Married & $35(38.9)$ & $55(61.1)$ & \\
\hline Widow and divorced & $9(27.3)$ & $24(72.7)$ & 0.43 \\
\hline \multicolumn{4}{|l|}{ Occupation } \\
\hline House wife & $24(30.5)$ & $66(69.5)$ & \\
\hline Employed & $11(50.0)$ & $11(50.0)$ & \\
\hline Retired & $4(57.1)$ & $3(42.9)$ & 0.10 \\
\hline \multicolumn{4}{|l|}{ Educational level } \\
\hline Illiterate & $3(12.0)$ & $22(88.0)$ & \\
\hline Basic & $27(36.5)$ & $47(63.5)$ & \\
\hline University and higher & $14(56.0)$ & $11(44.0)$ & $0.004^{*}$ \\
\hline \multicolumn{4}{|l|}{ Family monthly income in SR } \\
\hline$<5000$ & $13(26.0)$ & $37(74.0)$ & \\
\hline $5000-20,000$ & $28(40.0)$ & $42(60.0)$ & \\
\hline$>20,000$ & $3(75.0)$ & $1(25.0)$ & $0.04^{*}$ \\
\hline \multicolumn{4}{|l|}{ Family history of breast cancer } \\
\hline Yes & $15(57.7)$ & $11(42.3)$ & \\
\hline No & $29(29.6)$ & $69(70.1)$ & $0.01^{*}$ \\
\hline \multicolumn{4}{|l|}{ Having breast problem } \\
\hline Yes & $17(39.5)$ & $26(60.5)$ & \\
\hline No & $27(33.3)$ & $54(66.7)$ & 0.49 \\
\hline \multicolumn{4}{|l|}{ Contraceptive use } \\
\hline Users & $2(66.7)$ & $1(33.3)$ & \\
\hline Ex-users & $29(41.4)$ & $41(58.6)$ & \\
\hline No & $13(25.5)$ & $38(74.5)$ & 0.09 \\
\hline
\end{tabular}

*Significant. 
Table 3. Clinical breast examination among the studied women by their characteristics.

\begin{tabular}{|c|c|c|c|}
\hline \multirow{2}{*}{ Socio-demographic characteristics } & \multicolumn{2}{|c|}{ Clinical breast examination } & \multirow{2}{*}{$P$ value } \\
\hline & Yes $(n=34)$ & No $(n=90)$ & \\
\hline \multicolumn{4}{|l|}{ Age in years } \\
\hline$<40$ & $1(33.3)$ & $2(66.7)$ & \\
\hline $40 \leq 50$ & $19(32.2)$ & $40(67.8)$ & \\
\hline$\geq 50$ & $14(22.6)$ & $48(77.4)$ & 0.40 \\
\hline \multicolumn{4}{|l|}{ Nationality } \\
\hline Saudi & $29(30.5)$ & $66(69.5)$ & \\
\hline Non Saudi & $5(17.2)$ & $24(82.8)$ & 0.16 \\
\hline \multicolumn{4}{|l|}{ Marital status } \\
\hline Single & $0(0.0)$ & $1(100.0)$ & \\
\hline Married & $29(32.2)$ & $61(67.8)$ & \\
\hline Widow and divorced & $5(15.2)$ & $28(84.8)$ & 0.12 \\
\hline \multicolumn{4}{|l|}{ Occupation } \\
\hline House wife & $21(22.1)$ & $74(77.9)$ & \\
\hline Employed & $9(41.1)$ & $13(59.9)$ & \\
\hline Retired & $4(57.0)$ & $3(43.0)$ & $0.03^{*}$ \\
\hline \multicolumn{4}{|l|}{ Educational level } \\
\hline Illiterate & $5(20.0)$ & $20(80.0)$ & \\
\hline Basic & $21(28.9)$ & $53(71.1)$ & \\
\hline University and higher & $8(32.0)$ & $17(68.0)$ & 0.60 \\
\hline \multicolumn{4}{|l|}{ Family monthly income in SR } \\
\hline$<5000$ & $6(12.0)$ & $44(88.0)$ & \\
\hline $5000-20,000$ & $27(38.5)$ & $43(61.5)$ & \\
\hline$>20,000$ & $1(25.0)$ & $3(75.0)$ & $0.003^{*}$ \\
\hline \multicolumn{4}{|l|}{ Family history of breast cancer } \\
\hline Yes & $8(30.7)$ & $18(69.3)$ & \\
\hline No & $26(26.5)$ & $72(73.5)$ & 0.66 \\
\hline \multicolumn{4}{|l|}{ Having breast problem } \\
\hline Yes & $15(34.9)$ & $28(65.1)$ & \\
\hline No & $19(23.5)$ & $62(76.5)$ & 0.17 \\
\hline \multicolumn{4}{|l|}{ Contraceptive use } \\
\hline Users & $1(33.3)$ & $2(66.7)$ & \\
\hline Ex-users & $23(32.9)$ & $47(67.1)$ & \\
\hline No & $10(19.6)$ & $41(80.1)$ & 0.18 \\
\hline
\end{tabular}

${ }^{\star}$ Significant.

(57.0\%) and those with a monthly family income from 5000 - 20,000 SR (38.5\%) and those with monthly incomes of more than 20,000 SR (25\%). With no statistically significant differences, the proportion of clinical breast examination was also high among young aged women, Saudis, married women, basic and highly educated women, women with positive history for breast cancer, those with breast problems and users and ex-users of contraceptive pills.

Table 4 showed the distribution of the studied women by mammography practice and their characteristics. Of the studied women, there have been statistically significant differences between women who were practicing mammography for the first time and those reported frequent practice according to their educational level and monthly family income. The frequent mammography was more among the highly educated (56\%) and higher family income (66.7\%) 
Table 4. Frequency distribution of mammography among the studied women by their characteristics.

\begin{tabular}{|c|c|c|c|}
\hline \multirow{2}{*}{ Socio-demographic characteristics } & \multicolumn{2}{|c|}{ Mammography } & \multirow{2}{*}{$P$ value } \\
\hline & $1^{\text {st }}$ time $(\mathrm{n}=71)$ & Frequent $(n=53)$ & \\
\hline \multicolumn{4}{|l|}{ Age in years } \\
\hline$<40$ & $2(66.7)$ & $1(33.3)$ & \\
\hline $40 \leq 50$ & $34(57.6)$ & $25(42.4)$ & \\
\hline$\geq 50$ & $35(56.5)$ & $27(43.5)$ & 0.94 \\
\hline \multicolumn{4}{|l|}{ Nationality } \\
\hline Saudi & $55(57.8)$ & $40(42.3)$ & \\
\hline Non Saudi & $16(55.2)$ & $13(44.8)$ & 0.80 \\
\hline \multicolumn{4}{|l|}{ Marital status } \\
\hline Single & $1(1.00)$ & $0(0.0)$ & \\
\hline Married & $49(54.4)$ & $41(45.6)$ & \\
\hline Widow and divorced & $21(63.6)$ & $12(37.4)$ & 0.47 \\
\hline \multicolumn{4}{|l|}{ Occupation } \\
\hline House wife & $59(62.1)$ & $36(37.9)$ & \\
\hline Employed & $10(45.5)$ & $12(54.5)$ & \\
\hline Retired & $2(28.7)$ & $5(71.3)$ & 0.12 \\
\hline \multicolumn{4}{|l|}{ Educational level } \\
\hline Illiterate & $21(84.0)$ & $4(16.0)$ & \\
\hline Basic & $39(52.7)$ & $35(47.3)$ & \\
\hline University and higher & $11(44.0)$ & $14(56.0)$ & $0.01^{*}$ \\
\hline \multicolumn{4}{|l|}{ Family monthly income in SR } \\
\hline$<5000$ & $35(70.0)$ & $15(30.0)$ & \\
\hline $5000-20,000$ & $34(48.6)$ & $36(51.4)$ & \\
\hline$>20,000$ & $1(33.3)$ & $3(66.7)$ & $0.04^{*}$ \\
\hline \multicolumn{4}{|l|}{ Family history of breast cancer } \\
\hline Yes & $13(50.0)$ & $13(50.0)$ & \\
\hline No & $58(59.2)$ & $40(40.8)$ & 040 \\
\hline \multicolumn{4}{|l|}{ Having breast problem } \\
\hline Yes & $24(55.8)$ & $19(44.2)$ & \\
\hline No & $47(58.0)$ & $34(42.0)$ & 0.81 \\
\hline \multicolumn{4}{|l|}{ Contraceptive use } \\
\hline Users & $3(100.0)$ & $0(0.0)$ & \\
\hline Ex-users & $36(51.4)$ & $34(48.6)$ & \\
\hline No & $32(62.8)$ & $19(37.2)$ & 0.20 \\
\hline
\end{tabular}

*Significant.

women on the other hand; however, the proportion of women practicing mammography for the first time was higher in relation to other studied variables, although not significant.

Table 5 presented the barrier items preventing the studied women from contributing or conducting breast cancer screening. Among all of the studied women, the most important barrier items preventing women from practice breast self-examination were lack of awareness about this method (41.0\%) and not having breast lumps (21.8\%). The barrier items preventing the studied women to seek clinical breast examination were not having a breast lump (38.7\%) and lack of awareness (29.0\%). Among women who practice mammography for the first time during their life, the most important barriers to contribute frequent 
Table 5. Reasons of not performing breast cancer screening among the studied women.

\begin{tabular}{lc}
\hline Barrier items & $\mathbf{n}(\%)$ \\
\hline Breast self examination $(\mathbf{n}=124)$ & \\
1) Lacking of awareness & $51(41.0)$ \\
2) Not having breast problem & $27(21.8)$ \\
3) Forgetting to do it & $9(7.3)$ \\
4) Unimportant test & $4(3.2)$ \\
5) Fearing of finding lump & $2(1.6)$ \\
Clinical breast examination $(\mathbf{n}=124)$ & \\
1) Not having breast problem & $48(38.7)$ \\
2) Lacking of awareness & $36(29.0)$ \\
3) Embarrassment & $8(6.4)$ \\
4) Fearing of finding lump & $2(1.6)$ \\
Mammography ( $\mathbf{n}=71)^{*}$ & \\
1) Not having breast problem & $39(54.9)$ \\
2) Lacking of awareness & $29(40.9)$ \\
3) Not requested by doctor & $12(16.9)$ \\
4) Fearing of results & $2(2.8)$ \\
5) Fearing of pain & $1(1.4)$ \\
\hline
\end{tabular}

*Analyses including only those practice mammography for first time during their life time.

mammography were not having a breast lump (54.9), a lack of awareness $(40.9 \%)$ and not being requested by a doctor to do so (16.9\%).

\section{Discussion}

Globally, breast cancer is the second leading cause of death in women and ranked number one among cancerous diseases in women who live in Saudi Arabia [3] [4] [5]. The aim of this study was to investigate the attitude of women toward breast cancer screening. In the present study, breast self-examination, clinical breast examination and periodic mammography screenings were reported by $35.5 \%, 27.4 \%, 37.8 \%$ of women who participated in the study, respectively. The reported results of practicing breast cancer screening from other studies conducted in neighboring countries (Qatar and Jordan) showed BSE, CBE and periodic mammography screening were $13.9 \%, 31.3 \%$ and $26.9 \%$, respectively in Qatar [19], while 34.9\%, $16.8 \%$ and $8.6 \%$, respectively in Jordan [20]. Similarly, on regular performance of BSE, our data found $27.3 \%$ of participants have performed BSE once per month. However, previous study was conducted among Iranian women showed the regular performance of BSE was $10.1 \%$ [21]. Theses reported results reflect the differences of attitude toward BCS among different societies.

Regarding the performance of BSE, our findings in the present study emphasized the importance of social campaigns and mass media in teaching women the correct performance of practicing BSE. The data showed that the performance level of practicing BSE among the participants according to baseline technique of BSE was lacking, only 59\% of participants examine breast in lying down position, $77.3 \%$ raise their arm up and look for changes, $52.3 \%$ examine and press their nipple for any type of discharge and $73 \%$ examine lymph nodes in their armpit. 
Our data indicated that young women (less than 40 ) have $100 \%$ practicing BSE while $38.9 \%$ and $29.3 \%$ among 40 to less 50 year old and more than 50 year old women, respectively. These reported results were not in line with Ravichandran et al. study, where he found that there is no significant association between the different age groups and practicing BSE [10].

In our study, positive family history was remarkable and a promoting factor to keep practicing BSE among the participants. More than one half $(57.7 \%)$ of positive family history participants practiced BSE while only $29.6 \%$ of negative family history participants practiced BSE. As stated in study was conducted on 374 women in Riyadh, those woman who perceives family history as a risk factor that increases her susceptibility of having breast cancer would be more likely to be committed to do breast examinations in regular manner [22]. These findings reflect a positive attitude among women who have family history of breast cancer.

According to the present study more than half (56.0\%) of educated women (university and higher education) have a positive attitude about BSE. The data in this study showed practicing BSE were $30.5 \%, 50.0 \%$ and $57.1 \%$ for housewife, employed participants and retired respectively, this result was not in line with previous study that showed employment was the only significant socio-demographic predictor of BSE practice [22].

In terms of barrier for BSE, lacking awareness of this method (41.0\%) was the most important factor in not practicing BSE among the participants in this study. This proportion is much lesser than a study in Jeddah reported that $47.5 \%$ of females participants knew how to perform BSE [4]. As well, based on the study conducted in King Abdulaziz Medical City, Riyadh, Saudi Arabia, had shown that the reasons for not doing BSE as reported by 235 women were: not knowing how to examine their breast [22].

Despite breast cancer screening is being offered for free in our city, the study revealed that only $12 \%$ of the families with low monthly income $(<5000 \mathrm{SR})$ came for $\mathrm{CBE}$ and $30.0 \%$ of them came to do frequent mammography screening in comparable with $25 \%$ of high monthly income (>20,000 SR) came for CBC and $66 \%$ of them came to do frequent mammography screening. While in another study, found that the cost of screening had a crucial effect on women not seeking breast cancer screening [23].

Barriers preventing women from seeking clinical breast examination were: not having breast lumps (38.7\%) and lacking awareness (29.0\%). Similarly, a recent study reported that not having symptoms (92\%) and not knowing that screening was needed $(40 \%)$ were the main reasons for not undergoing either clinical breast examination or mammography [24].

In reference to another study, Women were not obtaining access to the screening program due to several factors, and most importantly, lack of education and awareness [15]. Data in this study were in concordance with the previous study which indicated that education level has a strong impact on women performance toward breast cancer screening. Out of 124 studied women, $56 \%$ of highly educated females do mammogram frequently, while only $16 \%$ of illiterate 
females do mammogram frequently. According to women who practiced mammography for first time, the data revealed not having a breast lump (54.9\%) is the most significant barrier that contribute doing frequent mammography. This is in contrast to another study, where lack of knowledge and awareness of breast screening were found to be the most important barrier [25].

The strengths of this study include that the study questionnaire was comprehensive and addressed almost all items as well as wide range of personal and belief barrier factors discussed in previously published Saudi and non-Saudi studies. The study questionnaire has also been validated by specialist in this filed; including radiologist, oncologist and an epidemiologist. To the best of our knowledge, this study is the first to study practice and barriers of different breast cancer screening methods in Medina region in Saudi Arabia. Dissemination of these findings to Medina Cancer Breast Screening Center (MCBSC) will help to know the current situation and to plan different breast awareness and health education programs to correct some incorrect beliefs preventing women in $\mathrm{Me}$ dina and to encourage them attending the center.

The limitations of this study should not be overlooked. Self-selection bias may have been a limitation factor in this study because all women were selected from single center, which should not attract women from different educational and family income sectors to attend. However, because of socio-demographic distributions observed in this study, the sample appeared representative and this factor appeared to have no role in the study findings.

\section{Conclusion}

Our results support the need for new emphasis in health educational program throughout promotion campaigns, mass media or even encouragement by health professionals; moreover, increase the nationwide breast cancer screening awareness to engage them in breast cancer preventive practice. Further research is needed to shed more light on this occurrence, particularly on Medina's population, and suggests future barriers and solution direction.

\section{Acknowledgements}

We are grateful to the healthcare providers at Taibah Breast Cancer Screening Center in Medina for their contributions to reach the goals of the study. The authors would like to thank all patients participated in this study.

\section{References}

[1] Mokdad, A.H., Jaber, S., Aziz, M.I.A., Al Buhairan, F., Al Ghaithi, A., Al Hamad, N.M., et al. (2014) The State of Health in the Arab World, 1990-2010: An Analysis of the Burden of Diseases, Injuries, and Risk Factors. Lancet, 383, 309-320. https://doi.org/10.1016/S0140-6736(13)62189-3

[2] El Bcheraoui, C., Basulaiman, M., Wilson, S., Daoud, F., Tuffaha, M., Al Mazroa, M.A., et al. (2015) Breast Cancer Screening in Saudi Arabia: Free but Almost No Takers. PLoS One, 10, e0119051. https://doi.org/10.1371/journal.pone.0119051

[3] Desouky, D.E. and Taha, A.A. (2015) Effects of a Training Program about Breast 
Cancer and Breast Self-Examination among Female Students at Taif University. The Journal of the Egyptian Public Health Association, 90, 8-13. https://doi.org/10.1097/01.EPX.0000460082.28774.71

[4] Radi, S.M. (2013) Breast Cancer Awareness among Saudi Females in Jeddah. Asian Pacific Journal of Cancer Prevention, 14, 4307-4312. https://doi.org/10.7314/APJCP.2013.14.7.4307

[5] American Cancer Society, Breast Cancer Facts and Figures (2012). http://www.cancer.org/research/cancerfactsfigures/breastcancerfactsfigures/breastca ncer-facts-and-figures-2011-2012

[6] Noroozi, A. and Tahmasebi, R. (2011) Factors Influencing Breast Cancer Screening Behavior among Iranian Women. Asian Pacific Journal of Cancer Prevention, 12, 1239-1244.

[7] Bleyer, A. and Welch, H.G. (2012) Effect of Three Decades of Screening Mammography on Breast Cancer Incidence. New England Journal of Medicine, 367, 1998 2005. https://doi.org/10.1056/NEJMoa1206809

[8] Rafi Baig, M., Subramaniam, V., Chandrasegar, A.A. and Mehmood Khan, T. (2011) A Population Based Survey on Knowledge and Awareness of Breast Cancer in the Suburban Females of Sungai Petani, Kedah, Malaysia. International Journal of Collaborative Research on Internal Medicine \& Public Health, 3, 671-679.

[9] Shapiro, S. (1977) Evidence on Screening for Breast Cancer from a Randomized Trial. Cancer, 39, 2772-2782.

https://doi.org/10.1002/1097-0142(197706)39:6<2772::AID-CNCR2820390665>3.0. CO;2-K

[10] Ravichandran, K., Al-Hamdan, N.A. and Mohamed, G. (2011) Knowledge, Attitude, and Behavior among Saudis toward Cancer Preventive Practice. Journal of Family and Community Medicine, 18, 135-142. https://doi.org/10.4103/2230-8229.90013

[11] Hussein, D.M., Alorf, S.H., Al-Sogaih, Y.S., Alorf, S.H., Alaskar, R.S., Al-Mahana, A.M., et al. (2013) Breast Cancer Awareness and Breast Self-Examination in Northern Saudi Arabia. A Preliminary Survey. Saudi Medical Journal, 34, 681-688.

[12] Latif, R. (2014) Knowledge and Attitude of Saudi Female Students towards Breast Cancer: A Cross-Sectional Study. Journal of Taibah University Medical Sciences, 9, 328-334. https://doi.org/10.1016/j.jtumed.2014.05.004

[13] Habib, F., Salman, S., Safwat, M. and Shalaby, S. (2010) Awareness and Knowledge of Breast Cancer among University Students in Al Madina Al Munawara Region. Middle East Journal of Cancer, 1, 159-166.

[14] Dandash, K.F. and Al-Mohaimeed, A. (2007) Knowledge, Attitudes, and Practices Surrounding Breast Cancer and Screening in Female Teachers of Buraidah, Saudi Arabia. International Journal of Health Sciences, 1, 61-71.

[15] Abulkhair, O.A., Al Tahan, F.M., Young, S.E., Musaad, S.M. and Jazieh, A.-R.M. (2010) The First National Public Breast Cancer Screening Program in Saudi Arabia. Annals of Saudi Medicine, 30, 350-357.

[16] Usta, Y.Y. (2012) Importance of Social Support in Cancer Patients. Asian Pacific Journal of Cancer Prevention, 13, 3569-3572. https://doi.org/10.7314/APJCP.2012.13.8.3569

[17] Jensen, L.F., Pedersen, A.F., Andersen, B. and Vedsted, P. (2015) Social Support and Non-Participation in Breast Cancer Screening: A Danish Cohort Study. Journal of Public Health $(O x f), 38,335-342$.

[18] SAS Institute Inc. (1999) Proprietary Software Release 8.2. SAS Institute Inc., Cary.

[19] Donnelly, T.T., Khater, A.-H.A., Al-Bader, S.B., Al Kuwari, M.G., Malik, M., Al- 
Meer, N., et al. (2014) Factors That Influence Awareness of Breast Cancer Screening among Arab Women in Qatar: Results from a Cross Sectional Survey. Asian Pacific Journal of Cancer Prevention, 15, 10157-10164. https://doi.org/10.7314/APJCP.2014.15.23.10157

[20] Abu-Helalah, M.A., Alshraideh, H.A., Al-Serhan, A.-A.A., Kawaleet, M. and Nesheiwat, A.I. (2015) Knowledge, Barriers and Attitudes towards Breast Cancer Mammography Screening in Jordan. Asian Pacific Journal of Cancer Prevention, 16, 3981-3990. https://doi.org/10.7314/APJCP.2015.16.9.3981

[21] Hajian Tilaki, K. and Auladi, S. (2015) Awareness, Attitude, and Practice of Breast Cancer Screening Women, and the Associated Socio-Demographic Characteristics, in Northern Iran. Iranian Journal of Cancer Prevention, 8, e3429. https://doi.org/10.17795/ijcp.3429

[22] Abolfotouh, M.A., BaniMustafa, A.A., Mahfouz, A.A., Al-Assiri, M.H., Al-Juhani, A.F. and Alaskar, A.S. (2015) Using the Health Belief Model to Predict Breast Self Examination among Saudi Women. BMC Public Health, 15, 1163. https://doi.org/10.1186/s12889-015-2510-y

[23] Wagner, M., Anderson K.H. and Broxton, L. (2016) Assessment of Barriers to Screening Mammograms for Rural, Poor, Uninsured Women and a Community Plan of Action. Journal of Community Health Nursing, 33, 42-53.

[24] Islam, R.M., Bell, R.J., Billah, B., Hossain, M.B. and Davis, S.R. (2016) Awareness of Breast Cancer and Barriers to Breast Screening Uptake in Bangladesh: A population Based Survey. Maturitas, 84, 68-74. https://doi.org/10.1016/j.maturitas.2015.11.002

[25] Mukem, S., Sriplung, H., McNeil, E. and Tangcharoensathien, V. (2014) Breast Cancer Screening among Women in Thailand: Analyses of Population Based Household Surveys. Journal of the Medical Association of Thailand, 97, 1106-1118.

Submit or recommend next manuscript to SCIRP and we will provide best service for you:

Accepting pre-submission inquiries through Email, Facebook, LinkedIn, Twitter, etc. A wide selection of journals (inclusive of 9 subjects, more than 200 journals)

Providing 24-hour high-quality service

User-friendly online submission system

Fair and swift peer-review system

Efficient typesetting and proofreading procedure

Display of the result of downloads and visits, as well as the number of cited articles

Maximum dissemination of your research work

Submit your manuscript at: http://papersubmission.scirp.org/

Or contact abcr@scirp.org 